\title{
Disclosure Needs and Motives After a Near-Death Experience
}

\author{
Regina M. Hoffman, Ph.D. \\ Louisiana State University
}

ABSTRACT: I analyze the communication processes used by 50 near-death experiencers and discuss their disclosure needs and motives, as well as influences and obstacles that affect disclosure habits. The findings suggest that disclosure needs evolve through stages after an experience, and reveal five distinct disclosure motives.

In the past fifteen years, the field of near-death studies has grown impressively. The term "near-death experience" (NDE), coined by Raymond Moody in 1975, has been popularized through print and other media, and for part of this past year a book on the topic seized the number one spot on the best-seller list. In addition to personal accounts, published research includes a substantial amount of research findings from scholars of various fields. A data base detailing the frequency and content of these reported happenings is now available. Building on this core research substructure, other scholars have ventured into interpretive endeavors as the effort to explore meaning and implications of these experiences continues.

While researchers have grown accustomed to refer to the NDE as if they could directly access its content, in fact our information about these experiences comes through the mediation of language. We rely totally on personal reports. It is the content of these reports, transmitted through narrative, survey, or interview responses, that provides researchers with data. Near-death experiences are certainly not

Regina M. Hoffman, Ph.D., is a Research Associate in the Department of Speech Communication at Louisiana State University. This article was based on research completed for her doctoral dissertation in communication theory at Louisiana State University. Reprint requests should be addressed to Dr. Hoffman at the Department of Speech Communication, Louisiana State University, Baton Rouge, LA 70803. 
the only phenomena that require this reliance on personal report. Within the medical arena, self-report is the singular means of access to a wide range of human experience. We study the human experience of pain through the communications of persons in distress, for instance, since "pain" is an interpretive attribution to a range of physical stimuli. Carol Zaleski (1987), in her book comparing neardeath experience narratives from modern and medieval times, explored some of the challenges embedded in the process of expressing "otherworld" experiences through spoken and written language.

Communications about important personal experience are also of interest to scholars in fields of psychology and interpersonal communication. These communicative acts often fall under the rubric of selfdisclosure, the revelation of information about the self that is verbally delivered, truthful, significantly revealing, and difficult or impossible to attain through other means (Adler, Rosenfeld, and Towne, 1986). More than twenty years ago, Sidney Jourard (1971), founder of modern self-disclosure research, speculated that the energy required to suppress important information about oneself translates into physiological stress. Augmenting his clinical insights with experiments, Jourard became convinced that decisions persons make regarding disclosure of important personal information carried broad implications for relationships, psychological well-being, and physical health.

Jourard's work inspired countless investigations into the nature and interpersonal dynamics regarding self-disclosure interactions. Today, self-disclosure occupies a central place in communication theory and in psychological explorations of privacy regulation. Within the past decade a new field, psychoneuroimmunology, has emerged. Some provocative discoveries regarding the link between disclosure habits and health have catapulted this topic into prominence and produced evidence supportive of Jourard's earlier speculations. These findings are vital and robust, moving one researcher to depart from his regular habit of publishing only in psychological journals in order to make these findings more accessible (Pennebaker, 1990). For persons who keep memories of traumatic experience under the cover of secrecy, this line of research holds particular significance.

In addition to challenges in interpretive and spiritual realms, neardeath experiences plunge individuals into profound communicative dilemmas concerning the revelation of this extraordinary happening. My awareness of the new research in psychoneuroimmunology coincided with some research I was conducting into linguistic challenges 
of near-death experience description and spurred me into an investigation of decisions persons make about revealing their near-death experience to others. That investigation became the nexus of my three-year dissertation project in communication theory (Hoffman, 1993).

\section{Self Disclosure: Risk and Benefit}

As with all scholarly research, an essential task in interpreting empirical findings involves a familiarity with conceptual definitions, with the ways basic concepts are operationalized in experimental conditions, and with the constraints that attenuate broader extensions of the findings. For these reasons, I want to define self-disclosure and examine the attendant risks and benefits associated with these pivotal communicative acts. In addition, I will differentiate between disclosure as an interpersonal activity and the translation of memory into language without an effort to present that material to another person.

Each human being has the right as well as the labor of regulating the psychological boundary between the inner, private world and the outer world of others. Perhaps the qualities of our modern society, where individuals dwell in relatively isolated conditions of privacy as compared with the openly tribal affiliations of earlier times, give this imaginary boundary greater psychological salience. The privacy guarantees typically found in Western society have created a situation wherein individuals may keep a substantial amount of personal experience shielded from the awareness of others. A specific communicative act is required to tell our inner "story."

Communication researchers focus on self-disclosure as an interpersonal activity in which an individual chooses to reveal personal information that would be difficult or impossible to know unless it was revealed by the individual him- or herself. In addition, self-disclosure is a communicative act in which the content carries enough significance that the speaker perceives that a level of risk or increased vulnerability is incurred by the act of sharing this with another. Typically, then, the issue of trust is raised and linked with the perceived degree of risk. A near-death experience is an excellent example of a self-disclosure topic. Experiencers typically consider the happening to be profoundly important, the topic is controversial, and its content cannot be known unless the experiencer reveals it first-hand. 
Because risk is an essential aspect of self-disclosure, it is compelling that individuals proceed with due care. Protection of that which is deemed valuable is legitimate and healthy. Indiscriminate self-disclosure is not encouraged. Even Jourard, who wrote about the "transparent self" (1971), encouraged selective disclosure. Writing about the value of privacy, Jourard praised legal protection of privacy that gave an individual the right to "choose the time and place for disclosure of his experience, as well as the company before whom such disclosures are made" (1966, p. 307). Research has found, for instance, that both extremely high and extremely low amounts of disclosure are negatively correlated with interpersonal attraction (Adler, Rosenfeld, and Towne, 1986). Self-disclosure is best conceived as an intricate and context-dependent interpersonal communication skill. Some trial and error may be required in the process of assessing acceptable risk, selecting trustworthy listeners, and monitoring depth of content revealed.

Research regarding self-disclosure within the field of interpersonal communication carries the assumption that content is intentionally shared with another person. With this assumption, issues such as listener response and perception of listener trustworthiness become crucial variables. Occasionally in psychological research, where selfdisclosure is called "disclosure" and "self-disclosure" intermittently, researchers try to eliminate the variables of listener response by creating experiments in which the listener is not visible to the speaker. In these experiments, the listener is behind a curtain, for instance, or not physically present at all, so that the "speaker" becomes the "writer" who deposits her or his revelation into a sealed box for later review. This latter condition occurs in some of James Pennebaker and associates' work (Pennebaker and Susman, 1988; Pennebaker, Kiecolt-Glaser, \& Glaser, 1988; Pennebaker, 1989; Pennebaker, 1990) as part of their effort to measure specific immune response without introducing confounding variables of listener response.

The identity and perceived characteristics of the person selected as target for one's self-disclosure has emerged as the most significant constituent in decisions of self-disclosure (Chelune, 1976; Wheeless, 1978; Brockhoeft, 1979). It is known, for example, that negative responses by listeners can pose additional burdens for self-disclosers. As Pennebaker and Susman (1988) and Pennebaker (1990) emphasized, personally devastating negative effects may follow when one is rejected during important disclosures. Women who were denounced following disclosures of incest, for instance, had "particularly long- 
term negative psychological and physical effects" (Pennebaker and Susman, 1988, p. 331).

While a mature approach to risk assessment is required when considering self-disclosure, recent findings have supported a model that strongly demonstrates the health benefits of "talking about or, in some way, confronting significant life experiences" (Pennebaker and Susman, 1988, p. 331). It appears that the "act of inhibiting ongoing behavior, emotions, and thoughts requires physiological work" (Pennebaker and Susman, 1988, p. 331). Of particular significance are those experiences that an individual thinks about often and wants to discuss with others, but actively refrains from doing so. Physiologically speaking, then, protection appears to be an ongoing process that exacts a price.

One study among survivors of childhood cancer found that communication patterns during treatment were the single best predictor of psychosocial outcome, while medical severity was less predictive (Fritz, Williams, and Amylon, 1988). Another study linked high blood pressure with lower levels of disclosure (Cumes, 1983). The recent collaborative work of Pennebaker and associates (Pennebaker and Susman, 1988; Pennebaker, Kiecolt-Glaser, and Glaser, 1988; Pennebaker, 1989; Pennebaker, 1990) represents the combined efforts of psychologists and immunologists to isolate the relationship between disclosure and physiological effect. This body of research provides the clearest model for "the physiological work of inhibition" (Pennebaker, 1989, p. 231) as well as the health and cognitive gains that follow "confrontation" through disclosure of previously withheld experiences.

Pennebaker (1990) reported his shock at the proportion of students in his samples who had experienced significant traumatic happenings. It is clear from the examples given that most subjects associated "trauma" with negative events, though in a wider sense trauma refers to "an emotional experience or shock, which has a lasting psychic effect" (Webster's Unabridged Dictionary, 1983). The greatest health benefits were noted for the group that discussed both relevant facts and feelings about the event (Pennebaker and Susman, 1988). These benefits persisted in spite of subjects reporting that they experienced anxiety and depression initially following disclosure about the experience. The work of these researchers "suggests the existence of a general disclosure motive" (Pennebaker and Susman, 1988). Pennebaker (1990) also emphasized that the process of encoding significant life events into language appears to offer specific advantages. 
Within the field of interpersonal communication, self-disclosure implicitly requires a receiver for the disclosure. That person may or may not be physically present during the revelation. In some of Pennebaker's experiments the subjects did not communicate face-to-face about their experiences, although in every case a subsequent reader or listener was expected to peruse the material. Pennebaker (1990) was convinced that the process of translating experience into language offers so many benefits that he recommended individuals do so whenever they find themselves ruminating about important life events, even if the material is never shared with another. I noticed that a number of near-death experiencers remarked to me that they had written a description of the happening. Within my study, however, I specifically focused on decisions NDErs made to communicate about the experience with another person.

\section{Research Description}

Considering the frequency with which near-death experiences occur (nearly 40 percent of cases in which individuals come close to death during a physical crisis) and the profound nature of these happenings, I find it intriguing to ponder the infrequency with which firsthand accounts are initiated. Cardiologist Michael Sabom (1982) reported, for instance, that when he first heard about near-death experiences at a church gathering he had never heard such a report first-hand before that time, though he had resuscitated more than a hundred patients. Sabom read Raymond Moody's book Life After Life (1975) "but remained unconvinced that it was nonfiction material" (Sabom, 1982, p. 3). Later when he pulled up a chair to his patients' bedsides and initiated the topic of memories from unconscious moments, Sabom was amazed to hear patient descriptions that corroborated Moody's findings.

In my research project, $I$ investigated the decisions persons make to talk about or not talk about their NDE. Generally, other researchers have characterized near-death experiencers as reluctant to initiate discussion about their remarkable experience, though no other researcher has conducted a thorough study into disclosure motives and practices among near-death experiencers (Hoffman, 1993). I hoped to understand these self-disclosure dynamics better in order to portray accurately experiencers' disclosure needs, motives, and habits. If experiencers reported that they frequently thought about 
this event and wanted to talk about it but faced formidable obstacles in doing so, then a significant disclosure dilemma exists for more than 12 million Americans. A better understanding of such communicative dilemmas could also shed light on how the burdens of secrecy might be lifted following these and other life-transforming events.

After a thorough review of current research literature about neardeath experiences, I located 50 persons who remembered a neardeath experience during a physical crisis and conducted lengthy interviews with each person. Following a description of the experience, I asked questions about the decisions they had made to talk about this happening with others, about the criteria they used to reach those decisions, and about the factors that contributed to a sense of satisfaction or dissatisfaction with those disclosure interactions.

This article addresses disclosure needs and disclosure motives reported by these individuals regarding their near-death experience. In a later article, I will describe the disclosure habits reported, including a discussion of factors that increase disclosure desire as well as obstacles that stand between a desire to disclose and a successful disclosure outcome. I will examine the issue of listener selection in that later article as well.

Locating and interviewing 50 near-death experiencers in my local metropolitan area required a period of twelve months. Rather than work through medical referrals, I chose to publicize my research project so that individuals would choose on their own to establish contact with me. My research description introduced my interest in meeting with persons who had experienced a near-death crisis and recalled happenings such as being outside the body, passing through a dark tunnel, facing a decision to return to this world, or seeing a being of light. My focus on decisions to talk about that experience was clearly stated in the research descriptions, and I indicated as well that I was interested in meeting with persons who had not talked about it as well as persons who had discussed it with others.

Initially, I circulated my research description to area churches and hospital bulletins. My home telephone number was included as well as the fact that this research formed my doctoral dissertation project. I also made presentations to various local groups and mentioned my research project during those events. Six months into my project our local newspaper published an article about my research; I received 63 telephone calls within five days following that news article and ultimately interviewed 28 of these callers. I stopped my official in- 
terviews after I had completed 50, although I had received calls from more than that number and still today receive calls from experiencers hoping to speak with me.

My interviews, typically lasting $1 \frac{1 / 2}{2}$ to 2 hours, followed the rubric of ethnographic qualitative methodology. Ethnographic research methodologies aim at learning from people their perspectives, emphasizing the powerful role that context and meaning occupy in human interaction. This methodology enables researchers to look at both the "what" and the "why" of human behavior. At the end of the interviews, experiencers completed Kenneth Ring's (1980) Weighted Core Experience Index (WCEI) as well as Bruce Greyson's (1983) NDE Scale. Other pen-and-paper questions about disclosure desire and habits were also presented following the interview. These instruments and questionnaires provided me with an opportunity for quantitative and statistical data in addition to the qualitative work of the interviews. A completely detailed description of research methodology and protocol can be found in my dissertation (Hoffman, 1993).

Within the group of 50 persons were 26 women and 24 men. Precipitating physical crises included illness (33 persons), accident (12), violent attack (4), and suicide attempt (1). The average age was 49.6 years, with the range extending from 21 to 72 years of age. Years of education ranged from 7 to 23 , with an average of 15.3 years. Occupations were quite diverse including sheriff, nurses, counselors, skilled laborers, Federal Bureau of Investigation agent, dentist, engineer, barber, accountants, office workers, minister, and teachers. The average lapse of time between the interview and the near-death experience was 16.2 years.

In terms of disclosure habits, this group represented a wide range as well. The research interview was the first disclosure about the NDE for three respondents. Another three persons had spoken about their experience to only one other person before the time of the interview. Of the group of 50, 15 (30 percent) had described their experience on five or fewer occasions before they met for the interview. Another 14 (28 percent) reported they had described their NDE to between six and 15 persons, while yet another 14 (28 percent) estimated that they had talked with 16 to 50 listeners about it. At the other end of the continuum, seven NDErs (14 percent) reported that they had described their experience to more than 50 listeners, including those occasions when they had spoken to groups.

For a few individuals, talking about the near-death experience merged with professional roles of ministering, nursing, and religious 
discussion leadership. A recovering alcoholic found that this experience formed a crucial part of his story told at Alcoholics Anonymous meetings. Because the group of individuals I interviewed included a full range of disclosure habits, from deeply reticent to freely disclosive, I was given insight into perceived risks as well as the accumulated expertise of those who had refined the skills necessary to speak about this topic comfortably.

While I did not check medical records to verify reported physical crises, I did ask respondents to complete Ring's WCEI and Greyson's NDE Scale to validate that these persons were indeed recalling an experience that matched the descriptions in research literature. Results confirmed that these remembered events were near-death experiences. Ring considered scores above 6 on his WCEI to reflect the presence of an NDE and scores above 9 a deep near-death experience. Of the 50 people I interviewed, 44 ( 88 percent) scored above 9 on that scale. The mean score on Greyson's NDE Scale for his original sample of NDErs was 15.01; the mean score for my group was a comparable 14.46. Four individuals reported to me that they had more than one near-death experience to talk about. One individual reported he had had more than 20 of these happenings before his cardiac condition was properly diagnosed and treated.

\section{Stages of Disclosure Needs}

As experiencers looked back over their disclosure habits, they often characterized their communicative needs in terms of stages. We made special efforts to reconstruct the initial disclosure event for those who had spoken about their experience before the time of the interview and to work forward in time from that first conversation. For those experiencers who had already chosen at least one opportunity to disclose their experience the vast majority could recall that initial decision with clarity. Usually the reaction of the listener was clearly remembered as well. Together we walked through the details of early disclosures and across the years that lapsed since the experience to discover critical variables in their decisions to talk about this happening.

Among those influences, for instance, were their particular needs to talk about the experience with another person. These needs for disclosure tended to shift over time. For individuals who appeared to have worked through several stages and reached a state of relative 
integration regarding this experience, disclosure urges that were originally experienced as "needs" transformed finally into a more gentle impulse described by them as "willingness" to talk about their near-death experience.

The five stages described below were characterized by compelling needs, particular difficulties, or requirements that needed resolution. Disclosure needs were experienced more as natural results or necessities than matters of simple conscious intentionality. Evolving through developmental phases and following inner rules of unfolding, disclosure needs may be clearly understood only in retrospect because they tend to function at a level more opaque than conscious intention.

For the three individuals who had never spoken about the experience in depth before they met with me, two had kept quiet because of their anticipation of negative reaction, while one had begun such a disclosure immediately upon regaining consciousness only to be told she would be "locked away" if she dared utter such remarks. For a few others, the initial conversations had been so unsatisfying that a cloak of silence fell upon them. Acute needs that they experienced had gone unmet. Early reactions that are interpreted as rejections or strongly devaluing responses have enormous power to impede subsequent disclosures.

Some experiencers, then, had been thwarted in meeting their disclosure needs, while others had been successful in meeting those needs through satisfying conversations with others. Broad patterns surfaced as they retraced needs to talk about the near-death experience. As with any major and sudden life event, a subsequent adjustment process ensues before integration is complete. The movement toward integration after near-death experiences appears to be influenced in part by the degree to which disclosure needs are met at key turning points.

\section{Shock/Surprise}

The days and weeks immediately following a near-death experience can be a period of intense dislocation. Some persons emphasize that it may take some time to feel securely identified with their physical body again. The famed psychiatrist Carl Jung, who was no stranger to numinous experiences before his own near-death experience during a heart attack, reported that "in reality a good three weeks were still to pass before I could truly make up my mind to live again. I 
could not eat because all food repelled me" (1961/1963, p. 292). Some experiencers emphasized the "coarseness" of the body afterwards in their discussions with me. One man asked me if $I$ had seen the old metal diving suit on display at the aquarium, claiming that one's body feels as heavy and clumsy as that metal suit after one has experienced freedom from its constraints.

Emotional highs and lows often mark the initial period following the experience as well. Because experiencers are struggling with recovery from the physical crisis as well, there's an interplay between two major adjustments at the same time. It's not uncommon for experiencers to credit their near-death experience with giving them strength to endure the recuperation process.

Some familiarity with near-death experiences in general can attenuate aspects of initial shock by eliminating the sense of singularity. For those who have never heard of near-death experiences before their own, a feeling of being alone with this extraordinary occurrence can seriously preoccupy and isolate them. But even the well-informed are unprepared for the astonishing power of a near-death experience.

I interviewed two persons who were not only informed but seriously interested in this topic before their own sudden onset of physical crisis. One man mused that after he had read Moody's book he had developed a certain set of expectations about the content of his own (eventual) walk across the threshold of death. His specific expectations were unmet. The power and beauty of his experience, however, in no way brought disappointment. He was left with a sense of humor about his limited understanding before the experience visited him first-hand.

Another man, a minister who regularly gave talks about death and near-death experiences, was struck down with a massive heart attack. Despite all his reading and speaking on the subject, he was completely unprepared for the wonder and glory of his encounter with Divine Being. Afterwards he characterized his faith as completely transformed, and expressed energetic eagerness to correct earlier misrepresentations of God.

During the early weeks, then, nearly all experiencers dwell in a state of relative shock or surprise. Running as a common thread is the need to respond to the awesome power of the near-death experience. The experience's power stays with them. Often they have long lonely hours of recovery to think about it. The experience has changed them, with varying degrees of profundity, and the full implications of this dramatic shift are unknown at first. Experiencers 
reported two forms that disclosure needs may take during this period: cherished, reverential silence; and urgent desire to express its power to others.

Some experiencers respond to the amazing power of this experience as a treasure to be honored with secret delight at first. They regard those early days, weeks, or months as a time of incubation, as if they reside in the embrace of a glorious and wonderful presence. They intuitively sense that this happening will leave them changed forever. Especially for those individuals who encountered a loving presence during their experience, the time spent quietly drinking of that powerful presence seems to be one way to allow inner strength to build before the changes must be fleshed out in detail. Functioning much like a honeymoon period, this time of intimate presence postpones interactive concerns that might dissipate or dilute the exchange of loving energy. One person said "I wanted to ponder it a while." Another explained, "This was such a powerful thing that I couldn't even speak of it; I didn't even tell [my husband] about it until months later."

For those who experience a strong desire to talk about the experience immediately, the power within can feel explosive in its urgency. Some speak about the happening unselectively to whoever happens to be present. For example, a man who met with me described how, still hooked up to equipment in the trauma room, he motioned for pen and paper and wrote, "I am not a body." The excitement and assurance that accompanies these initial unselective outbursts may sustain the momentum for a time, making the person almost oblivious to listener reaction at first. I believe that for the informed and alert medical professional, the early moments and days following a brush with death are teeming with clues that would enable us to identify those patients who had a near-death experience. It usually isn't long, however, before physical events tend to reestablish the experiencer's ground of identity back in the earthly realm. With that return to a physical reference plane, a return to selectivity in disclosure interactions ensues.

Many experiencers reported feeling an urgent need to talk about their extraordinary experience coupled with a certainty that they would be negatively judged if they dared to utter such thoughts. For instance, a man told me he thought about his autoscopic near-death experience every day for five years and never spoke of it until he happened to read an article in the newspaper about near-death experiences. Lack of previous knowledge about NDEs increases the 
likelihood of this early disclosure dilemma. A long period of suppression, denial, or excessive preoccupation with the experience may begin. As a researcher, I am most concerned about the well-being of this group of persons, because the mismatch between strong desire to disclose and no opportunity to disclose impels these individuals into a state of isolation about a major life experience. Those who begin speaking openly about their experience initially but encounter a strongly negative response or a negative response from an important person also may suddenly find themselves in this category, living with a monumental disclosure dilemma.

\section{Validation}

The need for validation usually follows the initial stage of shock or surprise. Previous knowledge of NDEs may mitigate this need to a degree, but the power of one's own experience's casts a new light upon information gathered previously. Validation efforts take many forms: reading, watching television programs, or speaking with a trusted loved one or a respected professional. The need to resolve the issue of singularity takes precedence during this stage. Why has this profound happening come to $m e$ ?

I found that this validation need placed the experiencer in a state of increased vulnerability in talking with others about this happening. The initial numinous "afterglow" is fading; the work of incorporating this extraordinary experience into one's personal identity and life direction now begins in earnest.

At this point experiencers want sound information about the experience and recognition of its profound importance to them. It's helpful if someone will listen completely to their account without interrupting them at first. Such a complete recount may take $\mathbf{3 0} \mathbf{~ m i n}$ utes or more, since both facts and feelings are involved as well as vast implications. Quite naturally experiencers often expect those with authority, such as medical professionals or hospital chaplains, to be knowledgeable. A patronizing response is alienating and unhelpful, experiencers claim.

A rejection at this stage can be a devastating experience, sending individuals into communicative isolation for decades afterwards. The experiencers who met with me reported that if there's a choice between what to believe-the truth of the experience or the words of an authority-the experience wins. Because near-death experiences 
typically involve core values and issues that shape life choices, communicative isolation may take a terrible toll, as several experiencers described to me. In the words of one of these:

What it does is it distances you from the person that you told .... It sends you back into your-the experience that you know is true, and say, well, you know, it's a loss of community with the living.

\section{Interpersonal Implications}

If needs associated with stages of shock/surprise and validation have been met, experiencers move into fleshing out the details of the experience's legacy on their everyday lives. As changes percolate through their interactions with others, experiencers come to grips with the way their changed behavior affects those around them. Spouses, friends, and coworkers may notice mood changes, or shifts in spiritual attitudes. Perhaps the experiencer is angry that he or she was resuscitated, or is experiencing severe "homesickness" for that place of peace. In some cases, the experience's effects directly alter the structure of intimate relationships, prompting queries from the experiencer's partner.

At this stage, experiencers begin to disclose selectively as they address and explain the changes brought about by their experience. More attentive to listener responses, situational variables, and their own motives at this stage, experiencers report a growing awareness of disclosure choices. A complex learning process begins. Some disclosure interactions turn out well, while other disclosures may be later regretted. A personal set of intuitive guidelines takes shape, as the experiencer's appreciation for listener needs and state of readiness sharpens. Situational cues such as timing, level of privacy, likelihood of interruption, and topic preparation are noticed in order to increase the chances that the disclosure interaction will be satisfying to them and meaningful to their listeners.

As the circle of those who have heard about the experience widens, others begin to hear of this event secondhand and experiencers must cope with direct questions about their experience. However unwittingly, the experiencer may become a sort of celebrity, receiving attention that may be unwanted and/or uncomfortable. Experiencers begin to notice the differences between initiating disclosures about their near-death experience and responding to direct questions from others about it. Communicatively, these are quite distinct challenges, 
especially if the near-death experience is viewed as an intimate and cherished happening.

\section{Active Exploration}

The interpersonal implications stage finds the experiencer discussing her or his experience in order to explain or address immediate changes. Many of the experiencers I met had accepted the mystery of this happening as well as the circle of foreseeable consequences it bestowed. Working out immediate consequences was a matter of integrity, a natural result of the experience's transformative power. Other persons in their lives who had also been greatly affected by these changes had been informed about the NDE. Having gained strong assurance about death from the experience, these experiencers may live with a relatively calm sense of general purposefulness as they move toward the final death passage that they no longer fear.

Another stage visits many experiencers, however. This period is characterized as an active, robust search for greater understanding and information. Until recent years, that search for written information posed formidable challenges, and experiencers found themselves reading in esoteric areas in order to find any description that remotely resembled what happened to them. More recently, the numerous books and articles offer succor to those hungry for information.

This exploration stage is distinct from others by the depth of investigative efforts. As experiencers plumb philosophic and spiritual implications, as well as issues of personal destiny, a psychologically tumultuous process of unlearning and rebuilding is required. As one woman expressed this process, some 30 years after her near-death experience in early adolescence, she has been taking a "sabbatical" from the Catholic church to try to resolve the two "different entities." "That God [in the NDE] was not the same God" as the "punishing God" she heard about in church:

It was like I learned, it was my first experience [the NDE] with Ah! This wonderful being, this wonderful God, this loving, caring, nurturing, being, and then to be pulled back into "ok, now today we're going to talk about how we get burned in hell."

This period of active exploration may begin because some of the implications they are struggling with in the aftermath of the experience will require major life adjustments like career changes, di- 
vorce, or religious affiliation adjustments. Not wanting to take such actions precipitously and aware that others are affected by these decisions, experiencers begin a period of more intense analysis of what happened to them. A major life crisis that heightens the importance of death or brings into question earlier conclusions can also trigger this intense search period; thus experiencers may cycle through stages of intense exploration interspersed with periods of relative resolution. For instance, a number of experiencers told me that the death of a loved one catapulted them into a more intense consideration of their own near-death experience, adding a tone of urgency that was new in their personal reaction. The completion or thwarting of one's perceived life-purpose can also bring a new phase of urgent exploration.

Sometimes the period of exploration begins as the spiritual consolation that originally lingered after the experience begins to recede. One young man described the process through which everyday experiences erode the full immediacy of the near-death experience:

At the time [of the NDE] there's no doubt, like doubt is a physical thing ..... When you come back there's no doubt because you just . . . you know you experienced this . . . . As you go along you have more body experiences that gives you more . . . like every week you live you have a whole new week of things to doubt with your body, and you have all that in between.

Of all the lingering issues that experiencers struggled with, the issue of identifying and fulfilling one's purpose for being in this world was by far the most compelling. For most experiencers, their extraordinary happening convinced them of the purposefulness of earthly existence in general and of their life on earth in particular. But a general conviction is distinct from specific guidance. What contribution am I called upon to make? Wanting to fulfill their destiny, experiencers at this stage may find these questions unshakable and urgent.

Such questions are not remarkable in themselves; spiritual traditions abound with these queries. We know that these issues contribute to the urgency of adolescence and the crush of mid-life crises. Discovering one's own unique purpose is, I would argue, a search of the highest order: complex, vital, solitary, intimate, exhilarating, humbling. Among the near-death experiencers I interviewed, I found a distinct level of willingness to fulfill that purpose, as well as a great deal of confusion about how to discover and fulfill it. This com- 
bination of willingness and confusion intensifies the dilemma and provides the psychological energy to continue the search.

This search for purpose may be limited to reading, but experiencers noted that in this period they hungered for "like-minded" others. Connections with others who are also interested in these issues of spirituality and unique purposefulness begin. Religious institutions vary in the priority and avenues given to these questions; a number of experiencers depart from prior religious affiliations, yet hunger for companionship during this search. Near-death experiencers know that their extraordinary encounter at death's door forms the nucleus of their personal odyssey. As trust builds and common ground is established, experiencers often trace their story through recounting that magnificent happening. Because the near-death experience so powerfully shapes who they are, what they believe, and how they feel about themselves, not to speak about it seems misleading or even deceitful. In this way, accounts of near-death experience surface in Alcoholics Anonymous groups, in church discussion settings, within therapeutic relationships, at New Age workshops, and so on.

\section{Integration}

The question of meaning eclipses other issues after the near-death happening. Experts may debate issues of cause, patterns, and interpretation, but the experience of living cannot be held in abeyance. Near-death experiencers must flesh out its meaning for them in the day-to-day events of their lives.

So wide is the scope of this extraordinary happening, that the shadow of its meaning informs even minute decisions and ordinary interaction. For instance, one woman claimed she felt "obligated to pay my phone bill on time," as well as "to be a good citizen . . . to vote ... to always be kind . . . to never take away human dignity ... to offer a loving hand if I can, without it being ego-centered" because she had freely chosen to return to her earthly existence.

At the integration stage, individuals know the deeper influence of this experience upon their choices of living. It has shaped them indelibly. The experience is neither forgotten nor at the forefront of their minds. Rather, it is woven imperceptibly into the fabric of who they are. A state of relative consonance is reached between explored 
beliefs and habits of living. They dwell, as it were, in a living relationship with the experience and accept its dynamic presence in their ongoing journey.

Disclosure needs have transformed into a general sense of willingness to talk about the experience. At the core of this new perspective is the issue of "ownership." While at first experiencers may have related to the experience as belonging to them, during integration experiencers recognize they don't have "ownership over this," as one man summarized it. Dwelling within a larger mystery, hoping that their everyday living remains faithful to the meaning of that mystery, experiencers surrender a measure of ego concerns that formerly shaped disclosure decisions.

One man, for instance, who had spoken to only three others about his NDE at the time of our interview, later began accepting invitations to speak about his experience. He explained his attitude after addressing a group in this way: "I never know who will benefit from hearing about this. If it helps even one person, who am I to withhold that comfort?" Another experiencer, a woman who met with me 20 years after her experience, said, "I don't know that I have changed anyone else's life, uh, that's not my concern. My concern is, for whatever reason, for whatever purpose, to be what $I$ feel is a vehicle."

\section{Disclosure Motives}

Disclosure needs move through stages and seem to function in developmental, global ways in fueling disclosure. Disclosure motives, on the other hand, are the hopes, goals, and intentions for specific interactions. Disclosures can be efforts to meet personal needs, but often disclosures are initiated in order to meet goals beyond the personal needs of the experiencer.

A motive shapes the expectations of the discloser and governs the process of listener selection. Subsequent assessments of satisfaction or dissatisfaction are shaped by disclosure motives. While disclosure needs are experienced as mercurial inner forces, disclosure motives can be articulated more easily as experiencers recount the specific interactions in which they discussed the near-death experience. Five sequences emerged as patterns when near-death experiencers described their past conversations about the NDE. The underlying motives for these sequences are the subject of this section. 


\section{Interaction with the Chronicle of Human Experience}

For persons who have little or no knowledge about near-death experiences before their own, in some way the chronicle of human experience-written and oral-has failed. As noted above, this experience may precipitate a kind of psychological shock. The most burdensome short-term legacy of having such an extraordinary experience may be the sense of singularity it bestows. This impression of uniqueness could be interpreted as spiritual distinction and/or painful alienation. Either way, the experiencer is left with a ponderous plight. As I have noted elsewhere (Hoffman, 1993, p. 149), "a search of 'the records' is in order."

Accessing the records of human experience about NDEs may take the form of locating written material or initiating oral communication. Both the goal of retrieving information from authoritative sources and the goal of registering one's experience into some form of reliable record surfaced as motives for these communicative interactions.

For purposes of gaining information, experiencers may want to question witnesses or request their medical records if their experience included a view of the resuscitation scene. Those experiencers who had transcendent near-death experiences search for those who they believe would be likely to know more about this happening. The most frequently mentioned professionals consulted included ministers, psychologists, nurses, psychiatrists, nuns, and doctors. For children ( 8 of the 50 persons I interviewed had their near-death experience before the age of 18 ), parents are often the authority figures chosen. As would be expected, experiencers meet with a variety of responses from those they consult seeking more information.

The desire to preserve an account of one's experience is a natural expression of the experience's value and the potential of such reports to assist others who will inevitably cross the same threshold called death. Such accounts may begin as entries in private journals or discussions with spouses and family. Often, however, these disclosures extend to more public written and oral forms. Experiencers report that they want the chronicle of human experience to reflect more faithfully the plenitude and tenor of these near-death passages. This motive surfaced frequently as a primary motive for picking up the telephone and contacting me, a local university researcher.

One person observed, "In general, I think the more people speak of these experiences, the better life is served in general. That's a 
huge statement, but I really think that's-that's true." Another experiencer noted:

Your request was interesting because we've learned so much, if people don't record the existence of the matter, then we will be so much the poorer. The experience, my experiences, good, bad, or indifferent, have to be recorded, have to be put forth in some logical, it's crass to say in some scientific way, in some logical system, so that it can be catalogued. This is important. If this little piece of information helps somebody, wonderful, that's fine. Because I've found it interesting over the years to be able to read of other's experiences.

Persons who had been outspoken skeptics about these kinds of experiences before their own spoke about their duty to "set the record straight." Two men who were known for their hard-nosed approach to reality were particularly outspoken about their near-death experience afterwards. Said one:

I've heard about out-of-body experience, where they are looking down, and can see themselves laying down there, and I used to laugh at that, thinking oh-kooks, you know. But I don't think that now . . . . People know me; I don't bull. You know, I'm not one to make up stories.

The other man explained his outspokenness with these words:

I'm known as a hard ass, ok? And everybody knows me .... I don't think anybody would think I was lying about it . . . . I don't know whether I'd believe or not [before my experience] but I know now that I'd believe them now.

When the sole motive for talking about one's experience is to enter the official chronicle of human experience, the interaction has a monologic quality to it. While the significance of the happening may be asserted, discussions of meaning that require intimate disclosure may not be dwelled upon.

\section{Integrity}

Frequently mentioned as the motive for discussing one's NDE was the matter of integrity. Going beyond simple honesty, experiencers accent the connection between others knowing them well and knowing about this experience that dramatically shaped them. One person said succinctly, "I don't think they could understand me until that." Another person expanded on this same idea: 
I feel like my personal integrity is important to me; my only reflection of me is me; it's the only thing I have. That's strange because I don't think I ever realized in my lifetime how lonely we're gonna be ... . You're everything you have, and that gets real scary because you think, me, I'm the only person I have . . . . It's like my personal integrity, as far as I'm concerned, means more to me than whatever my kids do.

For experiencers, integrity-a state of unbroken wholeness-seems to require some kind of match between outer honesty and inner perspective. For this reason, then, nearly every experiencer who was married at the time of their NDE disclosed this to her or his spouse. The experience is significant, valued, and intimate. The desire to share it with those who are also significant, valued, and intimate seems completely natural. The amount of detail varies depending on factors like initial reaction and perceived interest. Depth of disclosure is related to the depth of interest and acceptance the near-death experiencer perceives in the listener.

Experiencers mentioned this motive too in connection with decisions to talk about their NDE with those persons who are profoundly affected by the changes it suddenly caused in them. Sometimes disclosures prompted by integrity are begun in response to direct questions or expressions of frustration by others who are attempting to cope with these changes. At those junctures, the integrity issue makes responding a compelling impetus for disclosure.

\section{Helping Others}

Among the motives overtly acknowledged by the experiencers I interviewed, the most robust reason for speaking about their NDE was a willingness to help others. One legacy in particular follows neardeath experiences: fear of death is greatly reduced or eliminated. Appreciating the magnitude of that gift, experiencers would like to extend the benefits to others who are struggling with fear and anxiety about what lies beyond death.

Experiencers report that they are alert for clues that someone is both struggling with death fears and ready to talk about those fears. Sometimes the calm presence of an experiencer is judged to be more helpful than overt talk about the NDE. As one experiencer described his presence visiting a dying patient in the hospital: "I was drawing on the knowledge of my experience, but not divulging my experience." 
Another described her presence with these words: "Oftentimes when people are sick and are going to die and I've known them, and I know that they're particularly vulnerable, I go and sit with them ... . [Dying] isn't frightening." Said another, "Of all the things that came to me to say . . . . I said, You know, I really envy you the trip.' . . . Her eyes responded in such a way that I think she understood."

When experiencers talk about their NDE directly, the narrative is often tailored to meet the listener's needs and level of readiness. Experiencers, then, listen closely to decide first of all if a disclosure would be genuinely helpful and then what kind of narrative would best meet the listener's needs. These disclosures may be selective in content, limiting the revelation to those elements likely to meet the needs at hand. A combination of experience elements and meta-experience comments are typical, giving the near-death experiencer an opportunity to comment on the experience's hopeful legacy as well as certain specifics from their extraordinary encounter.

Experiencers are sometimes quite surprised at the power of this disclosure to bring comfort to others. An initial interaction, then, may inaugurate a greater willingness to talk about it when subsequent opportunities come their way. A few experiencers reported they became involved officially in hospice work, while others became known quietly for their gifts in working with terminally ill or dying persons. Unofficially and informally, they may be asked by physicians or ministers to pay a visit to a dying person. Among the experiencers I interviewed, a few were in the habit of responding on a more or less regular basis to requests like these. One man described his transition to a more open association with this experience when a reporter wanted to interview him about it. "If I say yes to this, I don't know where it's going to end .... I thought about it." Concluding that he didn't "have ownership over this," he agreed to the interview.

Surrendering to this mystery initiates a powerful shift in one's relationship to the experience. These persons don't abandon the sophistication they've accumulated through satisfying and unsatisfying experiences of talking about the NDE, but they relinquish the need to know about or control the gifts that flow to others through their willingness to share.

A woman who teaches religion described how she set aside one class during the year to talk about her experience, turning aside the eager requests of the youngsters wanting to be entertained with the tale before that day arrived. She admits to being teased about it by 
youngsters and adults at times. "It's hard when something is so dear to you and so important to you, and other people make light of it." She knows, too, that "ninety percent of it's gonna be over their head or go in one ear and out the other." I asked why she took the risk at all, and she replied:

But if it affects one person . . . maybe when this kid's thirty, and is dealing with the death of a loved one, or is dealing with a similar experience that I've had, they'll remember that and it will help them over it.

Another teacher described how he evolved his current habit of reserving his disclosure to the students until the annual school retreat. If individual students approach him privately, students coping with grief or depression or suicidal tendencies, he honors those specific requests freely and privately.

\section{Mutual Inquiry}

In part because these experiences have such power, some individuals choose to relate to the NDE as if it were not only authoritative but exhaustive. Warranted or not, some experiencers maintain an attitude of informing others and do not enter a stage of deep quest unless or until subsequent life experiences cast doubt on the finality of earlier conclusions. For those who do move into periods of active exploration, they participate in the perennial human quest for understanding about spiritual, paranormal, or self-awareness matters.

Two psychoanalysts, Raft and Andresen (1986), studied a group of near-death experiencers and distinguished between those who regarded their experience as a "religious conversion" that ended uncertainty and those who continued to pursue self-knowledge. The latter, they reported,

become very curious about themselves, and they create special states of mind in which they find access to mutative experiences of selfknowing. They also tolerate the sense of uncertainty that openness to new knowing requires. (p. 319)

I also noticed these distinctions among the persons I interviewed. In communicative terms, experiencers from the former group are more interested in telling others not only how it was for them but how it will be for all. The latter group moves more in the direction of dialogue, drawing on their own experience as authoritative for 
them but wanting to participate in the process of ongoing inquiry about these issues with others who are genuinely interested as well. Ongoing inquiry seldom involves doubts about the reality of the neardeath experience per se. But its meaning and vast implications shape subsequent investigation. This inquiry may be confined to private reading and reflection, but often involves dialogue with others that precipitated disclosure about one's near-death experience.

In addition to profound psychological dislocation, a near-death experience may also bring about social dislocation. It's likely, for instance, that one's circle of associates (personal and religious) held beliefs consonant with one's own before the NDE. When a near-death experience propels an individual into new beliefs and attitudes, he or she may begin a search for a new set of close others. Persons who respect both these queries and personal experience are welcome companions on this journey. Such companions may be difficult to locate.

One woman had accumulated a small library through her 36 years of reading in these areas. 'I think my feeling was I had to understand what death meant, so that I would understand what life meant. That was my whole question, right there." She described her frustration over the years as she encountered a general unwillingness to ponder these issues seriously. Many individuals spoke about their NDE as a touchstone they could return to during these personal upheavals as well as the cornerstone that directed their subsequent search.

A pilot and engineer that I interviewed described his efforts to understand what happened in this way:

I've done more reading about traveling at high speeds, and more reading about what happens when nerves deteriorate, looking for a physical explanation of what happened. The thing that keeps bugging me is the sensation of traveling at high speed and the distinct feeling of being somewhere. I think there can be no question, I felt that I had gone somewhere.

During our interview, he asserted his conviction that he had been out of his body during these happenings. When I mentioned the curious concept of still having clear thoughts while apart from the body, his eyes lit up as he realized the challenges that part of his experience posed for mind/brain distinctions. He thanked me for bringing up a new area which he wanted to think about in more depth.

A woman who had three NDEs at ages 4,16 , and 39 , described how she had spent years pursuing self-knowledge including relentless honesty concerning ego traps. She was not expecting packaged answers from our interview, but was delighted for opportunities to ex- 
plore issues regarding self-knowledge with anyone who possessed the willingness to look at these issues with candor. During our interview, she was as interested in speaking about this journey of self-awareness as she was about the specific happenings within her NDEs.

Exploratory interaction is a dialogue. Both speaking and listening play an important role, and there's a willingness to examine aspects of the near-death experience together with another. This conversation will not be one that ends all conversation by producing final answers, but will be a moment of mutuality in an ongoing process. Two traits are appreciated in the listener: genuine interest and knowledgeable awareness. In a sentiment echoed by others whom I interviewed, an experiencer summarized this legacy of her NDE with these words:

I also felt like too that I had been given a gift that was a real double-edged sword. That it (a) it opened up a whole new realm of possibilities, but it gave me no answers, and it didn't tell me where to find them.

\section{Anamnesis}

One person who met with me, a professor who was frequently approached with questions about his experience, had grown accustomed to streamlining his remarks in order to meet the listener's needs. He recounted a recent interaction in which a student approached him to talk about the NDE. The professor responded by saying, "Just ask me the questions you have and I'll be glad to answer them "The student didn't respond with a question, however. The professor recalls their dialogue in this way:

\footnotetext{
"No, no, I want to hear you tell it as you experienced it." I said [thought], "Well, this is a person with some presence." And I said, "Well, this might take thirty minutes," and he said, "Well, that's why I came during this time when there's an hour and a half. I really want to hear you tell it all."
}

The professor was impressed that this young man apparently could distinguish between talking about the near-death experience and returning to the experience through a full, unhurried narrative.

Lane (1988) wrote about sacred experience and argued that "meaningful experience is always 'placed' experience" (p. 5). Lane's work was not specifically about near-death experiences, although he used these experiences as prime examples of "limit-experiences" in his opening pages: 
This indefatigable effort to anchor meaning in place is particularly evident in personal narratives of religious experience. Knowing God, like falling in love or living through a near-death experience, is inescapably contextual. All limit-experiences cause us to gather up every thread of meaning from the context in which they occur. In our memories, therefore, we return first of all to the place "where it happened." (p. 5)

From my lengthy interviews with 50 near-death experiencers, I realized that talking about one's experience as a delimited event was a communicative process distinct from returning once again to that experience. One's near-death experience is embedded within a specific physical sequence of events and within an ongoing personal odyssey. What happened is important but what it means is even more important.

Pennachio (1986) investigated the similarity between near-death experiences and mystical experience and concluded that NDEs belong to the family of mystical experience. While some near-death experiences do not involve contact with an ineffable presence, a large percentage do include this encounter with numinous energy and vibrant mystery.

Narrative discourse opens the possibility of creating-or recreating-a world that one can enter through a shift in consciousness. This shift involves the movement away from the "observer" point of view required by evaluative, conceptual, or commentary discourse into an experience of full "participation." By retracing the sequence and placing ourselves once again in that contextual place, we open up the possibility of crossing the line between remembering and anamnesis, a particular kind of remembering where the past enters into the present and is experienced afresh. In an unpublished study of recounting sacred experience, I noted that while giving and receiving information may occur on one level, the substratum of the interaction is the hope of achieving that kind of direct knowledge we call "experience." Through reconnecting with that numinous reality, one is again immersed into relationship with the ineffable presence.

The experiencers I interviewed commented that it was unusual for them to relate the happening in full detail. They are fully aware that it is possible for them to talk about the near-death experience without entering it again. Yet when the opportunity presents itself for full recounting in a respectful communicative atmosphere, the door is opened for an amazing reentry into that numinous world. 
Lane's (1988) comments about the character of sacred space seem to apply to the process of narrative re-entry into mystical aspects of NDEs as well. Lane suggested four axioms to guide us in understanding the character of sacred space: (1) sacred space chooses us, it is not chosen; (2) sacred space consists of ordinary space ritually made extraordinary through acts such as waiting and silence; (3) one can tred upon sacred space without entering it, which means sacred space is intimately related to the person's state of consciousness, and (4) "the impulse of sacred place is both centripetal and centrifugal, local and universal" (p. 15).

For the most part, interviews were private, unhurried, and filled with reverence for this powerful happening. Many experiencers told me afterwards that such complete recall meant that they reexperienced that ineffable presence or powerful peace during our time together. I noted the "luminous" quality at those moments, as did Moody (1975). It seemed that the experiencer retraced the original sequence that led to the encounter with sacred presence, returning to that sacred "place" once again and surrendering to its mysterious vitality. That act of surrender was also an invitation to me as listener to join them in that sacred space. Silence during those moments served not merely to signal the insufficiency of words, but as a symbolic act of openness. For a few moments the person put aside "telling" - that state of consciousness that draws on our ordering capacity-so that the immediacy of experience is made possible once again.

Near-death experiencers can identify, I believe, with the aftereffects that Lane (1988) described as both "centripetal and centrifugal." After such numinous and sacred encounters, an experiencer yearns for that contact again, yet is also "broken-hearted to imagine that it can only be found there" (Hoffman, 1993, p. 183). A great paradox takes hold in the experiencers' lives. They want to return and visit that sacred place often, yet they also yearn for ways to manifest that reality in some meaningful form in their lives where they can also meet that living presence.

From my perspective as a listener, hearing a full, unhurried account of someone's near-death experience was an intimate experience. The process of gathering up threads of meaning often involved revelation of yearnings or regrets, and admissions of flaws or habits of heart. The experiencer entered a state of great personal vulnerability with me by disclosing at that depth. This dance of incurring risk and establishing trust evoked my own vulnerability as well. If the 
moment of sacred silence made its way into the space between us, I recognized it as an invitation to relinquish that state of consciousness that controls and distances through words. Having created an opening for that sacred presence to enter, we shared the awe of its great mystery together.

A woman, who had several NDEs, described how she detects signs of this in others' narratives:

I can listen, and even though they would choose different adjectives, it was that awe. And so if you watch a person who's done that, and if you listen to them, at some point they become almost tongue-tied or speechless because there are no words.

We so often think of silence as absence or emptiness. In the context of recounting sacred experience, silence can signal the fullest presence of all. While experiencers yearn for this kind of contact again, they know that it is not simply a matter of choosing to do so. As Lane (1988) emphasized, the "sacred" chooses the moment to reveal itself. Communicative qualities are not sufficient in themselves to recreate that intimate contact; however, they do serve as important steps toward openness and reverence. A shift in consciousness seems to be required, for instance, away from the observer status that keeps us safe and apart, towards the surrender necessary for participation.

Elements of reverence sanctify the interpersonal space, elements such as setting aside a place free from interruption, forgetting all preoccupation with hurry and tasks, and welcoming shared silence. It seems also that because this moment of recontact is filled with intimacy and meaning for near-death experiencers, they intuitively look for signs that a listener is capable of recognizing and accepting an invitation to join them in that sacred space.

\section{Summary}

Researchers have documented many aftereffects of near-death experiences, such as reduced fear of death, attitudes toward an afterlife, enhanced psychic abilities, and spiritual transformation. We've directed little attention, however, towards the communicative dilemmas that these experiences impose afterwards and the ways NDErs resolve those dilemmas. This research project, in which I located and interviewed 50 near-death experiencers, attempts to fill that gap. 
In this article I have briefly examined the research literature concerning the possible negative effects, psychological and physical, of withholding important information about oneself. I also introduced the central concept of self-disclosure, including a definition of this communicative process as well as discussing the attendant risks and benefits known to be associated with acts of revealing important information about oneself.

This investigation into communicative dilemmas following NDEs focused on disclosure needs and motives, as well as influences and obstacles that affect disclosure habits. Questions about the process of selecting listeners were included in this study as well. This article, the first of two on this topic, presented a discussion of disclosure needs that evolve through stages after a near-death experience. In addition I described five distinct disclosure motives consistently articulated by the experiencers I interviewed.

In a subsequent article, I will discuss findings concerning disclosure habits, presenting some quantitative results of this study that reveal specific influences on subsequent disclosure habits. I will also examine particular obstacles as articulated by the experiencers themselves, expand on the process of listener selection, and discuss choices of secrecy as well as disclosure.

\section{References}

Adler, R. B., Rosenfeld, L. B., and Towne, N. (1986). Interplay: The process of interpersonal communication (3rd ed.). New York, NY: Holt, Rinehart and Winston.

Brockhoeft, W. J. (1979). The relationship between self-disclosure and various aspects of mental health as a function of the interpersonal situation in which disclosure occurs. Unpublished doctoral dissertation, Louisiana State University, Baton Rouge, LA.

Chelune, G. J. (1976). A multidimensional look at sex and target differences in disclosure. Psychological Reports, 39, 259-263.

Cumes, D. P. (1983). Hypertension, disclosure of personal concerns, and blood pressure response. Journal of Clinical Psychology, 39, 376-381.

Fritz, G. K., Williams, J. R., and Amylon, M. (1988). After treatment ends: Psychosocial sequelae in pediatric cancer survivors. American Journal of Orthopsychiatry, 58, $552-561$.

Greyson, B. (1983). The Near-Death Experience Scale: Construction, reliability, and validity. Journal of Nervous and Mental Disease, 171, 369-375.

Hoffman, R. M. (1993). Disclosure decisions and patterns after a near-death experience. Unpublished doctoral dissertation, Louisiana State University, Baton Rouge, LA.

Jourard, S. M. (1966). Some psychological aspects of privacy. Law and Contemporary Problems, 31, 307-318.

Jourard, S. M. (1971). The transparent self (2nd ed.). New York, NY: Van Nostrand Reinhold. 
Jung, C. (1963). Memories, dreams, and reflections. (R. Winston and C. Winston, Trans.). New York, NY: Vintage Books. (Original work published 1961).

Lane, B. C. (1988). Landscapes of the sacred: Geography and narrative in American spirituality. New York, NY: Paulist Press.

Moody, R. A. (1975). Life after life. Covington, GA: Mockingbird Books.

Pennachio, J. (1986). Near-death experience as mystical experience. Journal of Religion and Health, 25, 64-72.

Pennebaker, J. W. (1989). Confession, inhibition, and disease. Advances in Experimental Social Psychology, 22, 211-244.

Pennebaker, J. W. (1990). Opening up: The healing power of confiding in others. New York, NY: William Morrow.

Pennebaker, J. W., Kiecolt-Glaser, J. K, and Glaser, R. (1988). Disclosure of traumas and immune function: Health implications for psychotherapy. Journal of Consulting and Clinical Psychology, 56, 239-245.

Pennebaker, J. W., and Susman, J. R. (1988). Disclosure of traumas and psychosomatic processes. Social Science and Medicine, 26, 327-332.

Raft, D., and Andresen, J. J. (1986). Transformations in self-understanding after neardeath experiences. Contemporary Psychoanalysis, 22, 319-340.

Ring, K. (1980). Life at death: $A$ scientific investigation of the near-death experience. New York, NY: Coward, McCann and Geoghegan.

Sabom, M. B. (1982). Recollections of death: A medical investigation. New York. NY: Harper and Row.

Webster's Unabridged Dictionary. (1983). New York, NY: New World Dictionaries/Simon and Schuster.

Wheeless, L. R. (1978). A follow-up study of the relationships among trust, disclosure, and interpersonal solidarity. Human Communication Research, 4, 143-157.

Zaleski, C. (1987). Otherworld journeys: Accounts of near-death experience in medieval and modern times. New York, NY: Oxford University Press. 